\section{Reply to the Response to Pande et al. by Jathar \& Patil}

\author{
Satish A. Pande ${ }^{1}$, Amit P. Pawashe ${ }^{2}$, Raju \\ Kasambe $^{3}$ \& Reuven Yosef 3,4 \\ 1,2 Ela Foundation, C-9 Bhosale Park, Sahakar Nagar-2, Pune, \\ Maharashtra 411009, India \\ ${ }^{3}$ Sevadal Mahila Mahavidyalaya, Sakkardara chowk, Umrer \\ Road, Nagpur, Maharashtra 440009, India \\ ${ }^{4}$ International Birding \& Research Centre in Eilat, P.O. Box 774, \\ Eilat 88000, Israel \\ Email: ${ }^{1}$ pande.satish@gmail.com, ${ }^{4}$ ryosef@eilatcity.co.il \\ (corresponding author),
}

a. We appreciate the effort that has been put into "researching" our paper (Pande et al. 2011) and adding to the information on this Critically Endangered species by Jathar \& Patil (2011).

b. We feel that without going into the field and watching the birds the arguments will remain semantic and unresolved.

c. We will be only too happy to recognize that we were wrong in our assumptions and the hybridization does not occur in the Forest Owlet. This will remove once and for all any doubts. However, it does require going into the field.

d. We prefer to abstain from mud-slinging because we believe in what we saw in the field and will be glad to stand corrected. However, we do not believe that wildlife in general, or "sexy" species in particular, be monopolized by a group of researchers or an organization.

e. However, we are also extremely glad to have raised the issue and that several readers-researchers

Date of publication (online): 26 May 2011

Date of publication (print): 26 May 2011

ISSN $0974-7907$ (online) | 0974-7893 (print)

Manuscript details:

Ms \# 02803

Received 13 May 2011

Citation: Pande, S.A., A.P. Pawashe, R. Kasambe \& R. Yosef (2011). Reply to the Response to Pande et al. by Jathar \& Patil. Journal of Threatened Taxa 3(5): 1804

Copyright: (c) Satish A. Pande, Amit P. Pawashe, Raju Kasambe \& Reuven Yosef 2011. Creative Commons Attribution 3.0 Unported License. JoTT allows unrestricted use of this article in any medium for non-profit purposes, reproduction and distribution by providing adequate credit to the authors and the source of publication.

\section{OPEN ACCESS | FREE DOWNLOAD}

have commented on the contents. We recognize that it is controversial but we also recognize the power of fair discussion in science. That means that we have the right to question any and all decisions made by authorities based on studies by other researchers, including yourselves, if the internal reports and publications are made available to the public or in the form of peer-reviewed publications.

f. Hopefully, the authorities will also recognize the importance of collecting field samples in order to answer the controversial questions - even if it is a Schedule I species! Adopting a hands-off policy because no one is ready to shoulder responsibility is not the way of the world.

g. We look forward to reading the respondents forthcoming publications in order to further understand the conclusions reached and the methods applied. We hope to learn from their expertise.

i. We invite the respondents to convene with us and to discuss our shortcomings, ideas and findings in a friendly manner.

j. We think that it would be a good idea to convene a (inter?) national symposium focused on the species. This will bring other researchers interested in the species, to learn from the experience of those who have worked closely with the Forest Owlet, and to enhance their conservation through knowledge and cooperation of all involved.

\section{REFERENCES}

Jathar, G. \& D. Patil (2011). A review of "Discovery of possible hybrid of the Critically Endangered Forest Owlet Athene blewitti and Spotted Owlet Athene brama from northern Maharashtra". Journal of Threatened Taxa 3(5): $1800-1803$

Pande, S.A., A.P. Pawashe, R. Kasambe \& R. Yosef (2011). Discovery of a possible hybrid of the Critically Endangered Forest Owlet Athene blewitti and Spotted Owlet Athene brama (Aves: Strigiformes) from northern Maharashtra, India. Journal of Threatened Taxa 3(4): 1727-1730.

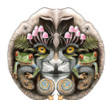

